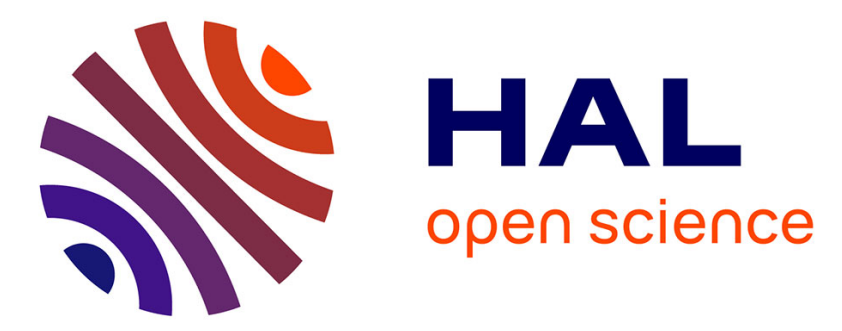

\title{
Different chemometric approaches to optimize the assay of St. John's Wort active ingredients
}

Guilhem Pages, Corinne Delaurent, Roger Phan-Tan-Luu, Michelle Sergent

\section{To cite this version:}

Guilhem Pages, Corinne Delaurent, Roger Phan-Tan-Luu, Michelle Sergent. Different chemometric approaches to optimize the assay of St. John's Wort active ingredients. Chemometrics and Intelligent Laboratory Systems, 2007, 86 (2), pp.159-167. 10.1016/j.chemolab.2006.06.006 . hal-02659854

\section{HAL Id: hal-02659854 \\ https://hal.inrae.fr/hal-02659854}

Submitted on 30 May 2020

HAL is a multi-disciplinary open access archive for the deposit and dissemination of scientific research documents, whether they are published or not. The documents may come from teaching and research institutions in France or abroad, or from public or private research centers.
L'archive ouverte pluridisciplinaire HAL, est destinée au dépôt et à la diffusion de documents scientifiques de niveau recherche, publiés ou non, émanant des établissements d'enseignement et de recherche français ou étrangers, des laboratoires publics ou privés. 


\title{
Different chemometric approaches to optimize the assay of St. John's Wort active ingredients
}

\author{
Guilhem Pages $^{\mathrm{a}, *}$, Corinne Delaurent ${ }^{\mathrm{a}}$, Roger Phan-Tan-Luu ${ }^{\mathrm{b}}$, Michelle Sergent ${ }^{\mathrm{b}}$ \\ ${ }^{a}$ Jeune Equipe 2421 Théorie Recherche Applications Concertées En Spectrométrie, Université Paul Cézanne, Avenue Escadrille Normandie-Niemen, \\ Case 511, 13397 Marseille Cedex 20, France \\ b Laboratoire de Méthodologie de la Recherche Expérimentale, Université Paul Cézanne, Avenue Escadrille Normandie-Niemen, 13397 Marseille Cedex 20, France
}

Received 16 January 2006; received in revised form 7 June 2006; accepted 7 June 2006

Available online 17 July 2006

\begin{abstract}
In this paper, we describe the optimization procedure for the quantitative assay of naphthodianthrones in St. John's Wort dry extract by reversed phase liquid chromatography. Lately, a project for European Pharmacopoeia monograph including an HPLC assay for the active moieties in St. John's Wort dry extract was published with a view to provoking reactions from other researchers. We therefore decided to use different chemometric approaches to evaluate the influence of both analytical and preparative factors to demonstrate the robustness of the optimized method. An asymmetric screening design was built in order to evaluate the weight of each level for each factor-the sonication duration, the light exposure duration, the flow rate and the type of column-on the response: the total hypericin content. Considering the results so obtained, we were compelled to modify some parameters. Thus we built a screening design to apprehend the reliability of the new sample pre-treatment process, the interpretation and identification of active factors were performed according to various methods. We used a third chemometric approach: a sequential bifurcation to check out the method's robustness. In a second step, an eluent compatible with Mass Spectrometry detection was determined by a combined design. To cope with both separation and analysis time, desirability functions were used. Optimal conditions are finally given by ternary system at an optimized temperature $\left(40^{\circ} \mathrm{C}\right)$ and all the naphthodianthrones are separated in 10 min on conventional endcapped octadecyl silica gel column.
\end{abstract}

(C) 2006 Elsevier B.V. All rights reserved.

Keywords: HPLC; St. John's Wort; Hypericum perforatum L.; Naphthodianthrones; Chemometric methodology; Desirability functions

\section{Introduction}

St. John's Wort (SJW-Hypericum perforatum L.) is a perennial aromatic plant, widely distributed in Europe, as well as in North America, Occidental Asia, Northern Africa and certain parts of Australia. If the therapeutic use of the $H$. perforatum L. has been known for 2000 years, it is because of its healing virtues, mainly due to hyperforin and flavonoids, and thus used to accelerate the cure of wounds, burns or ulcers [1]. The preparations for therapeutic use containing SJW are based on the flower extracts. These are generally standardized dry extracts containing between $0.15 \%$ and $0.30 \%$ of total

\footnotetext{
* Corresponding author. Tel.: +33 491288 643; fax: +33 491282897.

E-mail address: guilhem.pages@univ-cezanne.fr (G. Pages).
}

hypericins, one of the active ingredients [2-5] responsible for antidepressant effects.

To identify and characterize active principles of SJW extracts, several analytical techniques have been implemented. In HPLC, separations are carried out under reversed phase conditions, using octadecyl silica gels (ODS) in most of the quoted methods [6-12]. The mobile phases generally employed are complex and consisting of aqueous organic mixtures of acetonitrile and methanol $[11,13,14]$, or methanol and tetrahydrofurane [8].

Regarding to sample treatment, active ingredients are classically extracted by ethanol or methanol [11,13], acetone [15], but also by aqueous alcoholic mixtures [16]. This extraction step can be carried out under stirring at room temperature [17], or at temperatures between 50 and $100^{\circ} \mathrm{C}$ $[11,14]$, or by sonication [7,18]. Lately, Avasto and Guglielmi 
[19] have studied the influence of the type of extraction on the naphthodianthrones' content. The authors' conclusions are that a cold extraction with a polar solvent like methanol or ethanol is better to assay compounds while minimizing the amount of degradation products.

The absence of light is recommended in order to avoid the degradation of phloroglucinol derivative products and of the naphthodianthrones which are photosensitive $[7,18,20]$. Among these last compounds, the protopseudohypericin and the protohypericin are particularly unstable with light and are degraded respectively in pseudohypericin and hypericin.

Despite the wide range of chromatographic methods published in the scientific literature, all official Pharmacopeia monographs [16,21,22] still recommend a spectrophotometric assay of naphthodianthrones expressed as hypericin. The lack of specificity of this assay has encouraged European authorities to propose a new monograph [23] for comments. The originality of this monograph lies with naphthodianthrones from SJW dry extract assay by RPLC. The content is expressed in total hypericins, after identification of the peaks of first the hypericin, by an external calibration, and then of the pseudohypericin, using the relative retention time given from the hypericin retention time.

This paper deals with the use of different chemometric approaches to optimize analytical parameters and sample preparation conditions without introducing major modification to the reference monograph [23]. In a first part, three different experimental designs were implemented in order to optimize the proposed method and to validate its robustness [24-27]. In a second part, the nature of the buffer was modified to have less drastic conditions. An original combined design is used and then, desirability functions are applied to determine the eluent composition giving the best compromise between analysis time and resolution.

\section{Experimental}

All solvents used are HPLC grade. Water, methanol, ethyl acetate, monosodium phosphate, ammonium acetate and glacial acetic acid come from Merck (Darmstadt, Germany). Hypericin comes from Extrasynthèse (Genay, France). The SJW dry extract is provided by Laboratoire Distri B3 (Marseille, France).

The sample preparation in the reference monograph is to consider $70 \mathrm{mg}$ of SJW dry extract in $25.0 \mathrm{~mL}$ methanol, then to submit it to sonication, centrifugation and finally $2 \mathrm{~h}$ of light exposure without more details.

The assay solution is prepared according to the experimental design and the general process of sample preparation described in the reference monograph. The volume of the solution to be examined is completed to $25.0 \mathrm{~mL}$, before its injection in the chromatographic system.

All experiments were carried out on rigorously equivalent chromatographic systems (Merck, Darmstadt, Germany), composed of an L-6200A pump, an L-4200 detector, a D-2500 integrator, a Jetstream 2 oven and a Rhéodyne 772i valve (Rohnert Park, CA, United States of America) equipped with an injection loop of $20 \mu \mathrm{L}$. The three chromatographic columns used come from Merck (Darmstadt, Allemagne): Lichrospher ${ }^{\circledR}$ RP18 $250 * 4.6 \mathrm{~mm} * 5 \mu \mathrm{m}$, Lichrospher ${ }^{\circledR}$ RP $18 \mathrm{e} 250 * 4.6 \mathrm{~mm} * 5 \mu \mathrm{m}$ and SelectB ${ }^{\circledR} 250 * 4.6 \mathrm{~mm} * 5 \mu \mathrm{m}$. In the monograph, the mobile phase composition is a mixture of ethyl acetate/monosodium phosphate $(15.6 \mathrm{~g} / \mathrm{L})$ in water/methanol, 39/41/160, v/v/v. The eluent is a mixture of ethyl acetate/monosodium phosphate or ammonium acetate buffer/methanol with variable composition in function of the designed experiment. The flow rate is 0.7 or $1.0 \mathrm{~mL} / \mathrm{min}$ in function of the run and the detection wavelength is fixed at 590 or $593 \mathrm{~nm}$.

The experimental designs and the response treatments were carried out using Nemrodw software [28].

\section{Results and discussion}

This study is based on the RPLC assay described in the Pharmeuropa [23]. Since the pharmaceutical quality of extracts is usually standardized by controlling the content of naphthodianthrones, the chromatographic assay deals with the determination of these molecules. Experimental conditions of this monograph are reproduced in Experimental. One of the main drawbacks of this method initially seemed to be its lack of repeatability. Indeed, intra-assay precision is unacceptable with a relative standard deviation RSD of $7.5 \%$ for an average value of $0.26 \%$ of hypericins in the sample from six replicates.

A first chemometric study was investigating to apprehend the weight of each level attributed to five factors (Table 1) suspected to influence the intra-assay precision. Three of them (from $\mathrm{C}$ to $\mathrm{E}$ ) were selected because they were not detailed in the monograph. To control light exposure, all runs with the same type of natural light were realized simultaneously, in order to avoid variations in the light intensity from 1 day to another. This constraint limited the number of experiments in the design. The "artificial" level corresponds to a normal laboratory lighting exposure. The two other factors (A and B) were chosen in order to get optimized.

The grid detailing all the runs to be carried out is built on three 2-level factors, one 3-level factor and another 4-level one. Therefore an asymmetric screening design was built [29]. The optimal criteria imply an optimal experimental design with sixteen runs. The studied response is the content of total hypericins expressed in hypericin as recommended in the monograph. Table 2 gathers experiments and results. The "weight" of each factor was calculated from these results.

Table 1

Investigated factors in the asymmetric screening design

\begin{tabular}{|c|c|c|c|c|c|c|}
\hline \multirow[t]{2}{*}{ Factor } & \multirow[t]{2}{*}{ Name } & \multirow[t]{2}{*}{ Unit } & \multicolumn{4}{|l|}{ Level } \\
\hline & & & 1 & 2 & 3 & 4 \\
\hline A & Flow rate & $\mathrm{mL} / \mathrm{min}$ & 1.0 & 0.7 & & \\
\hline B & $\begin{array}{l}\text { Nature of the } \\
\text { stationary phase }\end{array}$ & & ODS & ODSe & & \\
\hline $\mathrm{C}$ & Magnetic stirring & & Yes & No & & \\
\hline $\mathrm{D}$ & $\begin{array}{l}\text { Sonication } \\
\text { duration }\end{array}$ & $\min$ & 5 & 15 & 30 & \\
\hline E & Light exposure & & Morning & Midday & Evening & Artificial \\
\hline
\end{tabular}


Table 2

Asymmetric screening design $2^{3} 3^{1} 4^{1} / / 16$

\begin{tabular}{|c|c|c|c|c|c|c|}
\hline \multirow[t]{2}{*}{ Run } & \multicolumn{5}{|l|}{ Factor } & \multirow{2}{*}{$\begin{array}{l}\text { Response } \\
\text { Hypericins } \\
(\%)\end{array}$} \\
\hline & $\begin{array}{l}\text { Flow } \\
\text { rate } \\
(\mathrm{mL} / \mathrm{min})\end{array}$ & $\begin{array}{l}\text { Nature of the } \\
\text { stationary } \\
\text { phase }\end{array}$ & $\begin{array}{l}\text { Magnetic } \\
\text { stirring }\end{array}$ & $\begin{array}{l}\text { Sonication } \\
\text { duration } \\
\text { min }\end{array}$ & $\begin{array}{l}\text { Light } \\
\text { exposure }\end{array}$ & \\
\hline 1 & 1.0 & ODSe & No & 5 & Morning & 0.27 \\
\hline 2 & 0.7 & ODS & No & 15 & Morning & 0.25 \\
\hline 3 & 1.0 & ODS & Yes & 30 & Morning & 0.31 \\
\hline 4 & 0.7 & ODSe & Yes & 30 & Morning & 0.28 \\
\hline 5 & 1.0 & ODSe & No & 5 & Midday & 0.35 \\
\hline 6 & 1.0 & ODS & Yes & 15 & Midday & 0.27 \\
\hline 7 & 0.7 & ODSe & Yes & 15 & Midday & 0.30 \\
\hline 8 & 0.7 & ODS & No & 30 & Midday & 0.32 \\
\hline 9 & 0.7 & ODS & Yes & 5 & Evening & 0.26 \\
\hline 10 & 1.0 & ODSe & Yes & 5 & Evening & 0.30 \\
\hline 11 & 1.0 & ODS & No & 15 & Evening & 0.29 \\
\hline 12 & 0.7 & ODSe & No & 30 & Evening & 0.30 \\
\hline 13 & 0.7 & ODS & Yes & 5 & Artificial & 0.37 \\
\hline 14 & 1.0 & ODS & No & 5 & Artificial & 0.25 \\
\hline 15 & 1.0 & ODSe & Yes & 15 & Artificial & 0.25 \\
\hline 16 & 0.7 & ODSe & No & 15 & Artificial & 0.28 \\
\hline
\end{tabular}

For such an asymmetric screening design, with qualitative factors and any number of levels, the model can be expressed as follows [30]:

$$
\begin{aligned}
\eta= & \operatorname{cst}+\alpha_{1} A_{1}+\alpha_{2} A_{2}+\beta_{1} B_{1}+\beta_{2} B_{2}+\chi_{1} C_{1}+\chi_{2} C_{2} \\
& +\delta_{1} D_{1}+\delta_{2} D_{2}+\delta_{3} D_{3}+\varepsilon_{1} E_{1}+\varepsilon_{2} E_{2}+\varepsilon_{3} E_{3}+\varepsilon_{4} E_{4}
\end{aligned}
$$

where $\eta$ is the theoretical response, $\alpha_{1}, \alpha_{2}, \beta_{1}$ are theoretical coefficients and $A_{1}, A_{2}, B_{1}, B_{2}$ take values of 1 or 0 either respectively when the corresponding level is present or notonly one level can be present.

Taking into account this interdependence of the variable levels, the general model may be reduced to a reference state model:

$$
\begin{aligned}
\eta= & \operatorname{cst}+\alpha_{1} A_{1}+\beta_{1} B_{1}+\chi_{1} C_{1}+\delta_{1} D_{1}+\delta_{2} D_{2}+\varepsilon_{1} E_{1} \\
& +\varepsilon_{2} E_{2}+\varepsilon_{3} E_{3}
\end{aligned}
$$

From the experimental results, the coefficients $a_{1}, b_{1}, c_{1}, d_{1}$, $d_{2}, e_{1}, e_{2}, e_{3}$, estimates of the theoretical values, have been calculated by least squares regression and are reported in Table 3 . These coefficients represent the response variation observed between the different factor levels. For example, considering the

Table 3

Estimated coefficients related to the asymmetric screening design

\begin{tabular}{|c|c|c|c|c|}
\hline \multirow[t]{2}{*}{ Factor } & \multirow[t]{2}{*}{ Name } & \multirow[t]{2}{*}{ Unit } & \multicolumn{2}{|l|}{ Level } \\
\hline & & & $(-)$ & $(+)$ \\
\hline$U_{1}$ & Flow rate & $\mathrm{mL} / \mathrm{min}$ & 1.0 & 0.7 \\
\hline$U_{2}$ & Stationary phase & & Base-deactivated & ODSe \\
\hline$U_{3}$ & Magnetic stirring & & No & Yes \\
\hline$U_{4}$ & Type of glassware & & Beaker & $\begin{array}{l}\text { Graduated } \\
\text { flask }\end{array}$ \\
\hline$U_{5}$ & Buffer concentration & $\mathrm{g} / \mathrm{L}$ & 13.6 & 15.6 \\
\hline$U_{6}$ & Sonication duration & $\min$ & 15 & 10 \\
\hline$U_{7}$ & Type of light & & Light bulb & Neon \\
\hline$U_{8}$ & Centrifugal duration & $\min$ & 5 & 2 \\
\hline$U_{9}$ & Centrifugal speed & & 2000 & 1000 \\
\hline$U_{10}$ & Solution filtrate & & Yes & No \\
\hline$U_{11}$ & Wavelength & $\mathrm{nm}$ & 593 & 590 \\
\hline$U_{12}$ & Light exposure duration & & $1 \mathrm{~h} 45 \mathrm{~min}$ & $2 \mathrm{~h}$ \\
\hline$U_{13}$ & Precolumn & & No & Yes \\
\hline$U_{14}$ & Solvent quality & & HPLC & Analysis \\
\hline$U_{15}$ & $\begin{array}{l}\text { Ethyl acetate volume in } \\
\text { mobile phase }\end{array}$ & $\mathrm{mL}$ & 40 & 50 \\
\hline$U_{16}$ & $\begin{array}{l}\text { Buffer volume in mobile } \\
\text { phase }\end{array}$ & $\mathrm{mL}$ & 40 & 50 \\
\hline$U_{17}$ & Column temperature & ${ }^{\circ} \mathrm{C}$ & 40 & 45 \\
\hline$U_{18}$ & $\begin{array}{l}\text { Standard solution } \\
\text { concentration }\end{array}$ & $\mu \mathrm{g} / \mathrm{mL}$ & 3 & 5 \\
\hline
\end{tabular}

\begin{tabular}{lr}
\hline Coefficient & \multicolumn{1}{c}{ Value } \\
\hline Constant & 0.310 \\
$a_{1}$ & -0.008 \\
$b_{1}$ & -0.001 \\
$c_{1}$ & +0.004 \\
$d_{1}$ & -0.003 \\
$d_{2}$ & -0.036 \\
$e_{1}$ & -0.020 \\
$e_{2}$ & +0.022 \\
$e_{3}$ & -0.009 \\
\hline
\end{tabular}

Table 4

Factors studied in both Plackett and Burman design and sequential bifurcation

factor A (flow rate), the response variation between level 2 and level 1 is -0.008 .

We can conclude that the type of support, the flow rate, and the agitation, at the different tested levels do not influence the hypericin content. The sonication induces the same response for durations of 5 or $30 \mathrm{~min}$ but the hypericin quantity decreases when sonication lasts $15 \mathrm{~min}$. On the other hand, the light exposure influences the response. As expected, midday light gives a value higher than those of other set natural light levels. These results suggest that the use of natural light is incompatible with reproducibility in terms of precision between laboratories located in some different places where the sunlight may be different.

In a second step, we wanted to apprehend the reliability of the method when overcoming the natural light exposure. Removing the daylight factor allowed us to increase the number of runs to carry out and consequently the number of factors to study. As previously, the factors and their levels were chosen in order to fill the missing details in the monograph. Moreover, we tested two different chromatographic supports (endcapped ODS and base-deactivated gel) to generalize the method with different material used under reversed phase conditions. Finally eighteen 2-level factors were selected (Table 4). The chosen experimental design consisted of a Plackett and Burman screening design with twenty runs $\left(2^{18} / / 20\right)$. Total hypericins content expressed in hypericin was the studied response and the results are reported in Table 5, with the experimental plan.

The mathematical model associated to Plackett and Burman [31] screening design is an additive model:

$\eta=\beta_{0}+\beta_{1} X_{1}+\beta_{2} X_{2}+\beta_{3} X_{3}+\beta_{4} X_{4}+\beta_{5} X_{5}+\ldots+\beta_{18} X_{18}$ 
Table 5

Plackett and Burman design $\left(2^{18} / / 20\right)$

\begin{tabular}{|c|c|c|c|c|c|c|c|c|c|c|c|c|c|c|c|c|c|c|}
\hline \multicolumn{18}{|l|}{ Factor } & \multirow{2}{*}{$\begin{array}{l}\text { Response } \\
\begin{array}{l}\text { Hypericins } \\
(\%)\end{array}\end{array}$} \\
\hline $\begin{array}{l}\text { Flow rate } \\
(\mathrm{mL} / \mathrm{min})\end{array}$ & $\begin{array}{l}\text { Stationary } \\
\text { phase }\end{array}$ & $\begin{array}{l}\text { Magnetic } \\
\text { stirring }\end{array}$ & $\begin{array}{l}\text { Type of } \\
\text { glassware }\end{array}$ & $\begin{array}{l}\text { Phosphate } \\
\text { buffer } \\
\text { concentration } \\
(\mathrm{g} / \mathrm{L})\end{array}$ & $\begin{array}{l}\text { Sonication } \\
\text { duration } \\
\text { min }\end{array}$ & $\begin{array}{l}\text { Type of } \\
\text { light }\end{array}$ & $\begin{array}{l}\text { Centrifugal } \\
\text { duration } \\
\text { min }\end{array}$ & $\begin{array}{l}\text { Centrifugal } \\
\text { speed }\end{array}$ & $\begin{array}{l}\text { Solution } \\
\text { filtrate }\end{array}$ & $\begin{array}{l}\text { Wavelength } \\
(\mathrm{nm})\end{array}$ & $\begin{array}{l}\text { Light } \\
\text { exposition } \\
\text { duration } \\
\text { (h) }\end{array}$ & Precolumn & $\begin{array}{l}\text { Solvent } \\
\text { quality }\end{array}$ & $\begin{array}{l}\text { Ethyl } \\
\text { acetate } \\
\text { volume } \\
\text { in mobile } \\
\text { phase }(\mathrm{mL})\end{array}$ & $\begin{array}{l}\text { Phosphate } \\
\text { buffer } \\
\text { volume } \\
\text { in mobile } \\
\text { phase }(\mathrm{mL})\end{array}$ & $\begin{array}{l}\text { Column } \\
\text { temperature } \\
\left({ }^{\circ} \mathrm{C}\right)\end{array}$ & $\begin{array}{l}\text { Standard } \\
\text { solution } \\
\text { concentration } \\
(\mu \mathrm{g} / \mathrm{mL})\end{array}$ & \\
\hline 0.7 & ODSe & No & Beaker & 13.6 & 15 & Light bulb & 5 & 2000 & Yes & 593 & $1 \mathrm{~h} 45 \mathrm{~min}$ & No & HPLC & 40 & 40 & 40 & 5 & 0.27 \\
\hline 1.0 & B-d & No & G-f & 13.6 & 10 & Light bulb & 5 & 2000 & No & 590 & $2 \mathrm{~h}$ & Yes & Analysis & 40 & 40 & 40 & 3 & 0.26 \\
\hline 0.7 & B-d & Yes & Beaker & 15.6 & 15 & Neon & 5 & 2000 & Yes & 590 & $2 \mathrm{~h}$ & No & Analysis & 50 & 40 & 45 & 3 & 0.25 \\
\hline 0.7 & ODSe & Yes & Beaker & 13.6 & 10 & Light bulb & 5 & 1000 & No & 593 & $1 \mathrm{~h} 45 \mathrm{~min}$ & Yes & Analysis & 50 & 50 & 45 & 3 & 0.23 \\
\hline 0.7 & ODSe & Yes & G-f & 13.6 & 10 & Neon & 2 & 2000 & No & 590 & $2 \mathrm{~h}$ & No & HPLC & 40 & 50 & 45 & 5 & 0.20 \\
\hline 1.0 & B-d & No & Beaker & 15.6 & 10 & Neon & 2 & 1000 & No & 593 & $1 \mathrm{~h} 45 \mathrm{~min}$ & No & Analysis & 40 & 40 & 45 & 5 & 0.25 \\
\hline 1.0 & ODSe & Yes & G-f & 13.6 & 15 & Neon & 2 & 1000 & Yes & 593 & $2 \mathrm{~h}$ & Yes & Analysis & 50 & 40 & 40 & 5 & 0.23 \\
\hline 1.0 & ODSe & No & Beaker & 15.6 & 10 & Light bulb & 2 & 1000 & Yes & 590 & $2 \mathrm{~h}$ & No & HPLC & 50 & 50 & 40 & 3 & 0.25 \\
\hline 0.7 & B-d & No & G-f & 15.6 & 15 & Neon & 5 & 1000 & No & 590 & $1 \mathrm{~h} 45 \mathrm{~min}$ & Yes & HPLC & 50 & 50 & 40 & 5 & 0.25 \\
\hline 1.0 & B-d & Yes & G-f & 15.6 & 15 & Light bulb & 2 & 2000 & Yes & 593 & $1 \mathrm{~h} 45 \mathrm{~min}$ & Yes & HPLC & 40 & 50 & 45 & 3 & 0.25 \\
\hline 1.0 & ODSe & Yes & Beaker & 15.6 & 15 & Light bulb & 5 & 1000 & No & 590 & $2 \mathrm{~h}$ & Yes & HPLC & 40 & 40 & 45 & 5 & 0.25 \\
\hline 1.0 & ODSe & Yes & G-f & 15.6 & 10 & Neon & 5 & 2000 & No & 593 & $1 \mathrm{~h} 45 \mathrm{~min}$ & No & HPLC & 50 & 40 & 40 & 3 & 0.20 \\
\hline 0.7 & ODSe & No & Beaker & 15.6 & 15 & Neon & 2 & 2000 & No & 593 & $2 \mathrm{~h}$ & Yes & Analysis & 40 & 50 & 40 & 3 & 0.22 \\
\hline 0.7 & B-d & No & G-f & 13.6 & 15 & Light bulb & 2 & 1000 & No & 593 & $2 \mathrm{~h}$ & No & HPLC & 50 & 40 & 45 & 3 & 0.29 \\
\hline 0.7 & B-d & Yes & G-f & 15.6 & 10 & Light bulb & 5 & 1000 & Yes & 593 & $2 \mathrm{~h}$ & No & Analysis & 40 & 50 & 40 & 5 & 0.30 \\
\hline 1.0 & B-d & Yes & Beaker & 13.6 & 15 & Light bulb & 2 & 2000 & No & 590 & $1 \mathrm{~h} 45 \mathrm{~min}$ & No & Analysis & 50 & 50 & 40 & 5 & 0.26 \\
\hline 1.0 & ODSe & No & G-f & 13.6 & 15 & Neon & 5 & 1000 & Yes & 590 & $1 \mathrm{~h} 45 \mathrm{~min}$ & No & Analysis & 40 & 50 & 45 & 3 & 0.22 \\
\hline 0.7 & ODSe & No & G-f & 15.6 & 10 & Light bulb & 2 & 2000 & Yes & 590 & $1 \mathrm{~h} 45 \mathrm{~min}$ & Yes & Analysis & 50 & 40 & 45 & 5 & 0.26 \\
\hline 0.7 & B-d & Yes & Beaker & 13.6 & 10 & Neon & 2 & 1000 & Yes & 590 & $1 \mathrm{~h} 45 \mathrm{~min}$ & Yes & HPLC & 40 & 40 & 40 & 3 & 0.25 \\
\hline 1.0 & B-d & No & Beaker & 13.6 & 10 & Neon & 5 & 2000 & Yes & 593 & $2 \mathrm{~h}$ & Yes & HPLC & 50 & 50 & 45 & 5 & 0.26 \\
\hline
\end{tabular}

B-d is for base-deactivated and G-f for graduated flask. 
Table 6

Coefficient estimates corresponding to the Plackett and Burman design

\begin{tabular}{lr}
\hline Coefficient & \multicolumn{1}{c}{ Value } \\
\hline$b_{0}$ & 0.2470 \\
$b_{1}$ & -0.0055 \\
$b_{2}$ & -0.0149 \\
$b_{3}$ & 0.0056 \\
$b_{4}$ & -0.0024 \\
$b_{5}$ & 0.0010 \\
$b_{6}$ & 0.0008 \\
$b_{7}$ & 0.0132 \\
$b_{8}$ & 0.0021 \\
$b_{9}$ & -0.0046 \\
$b_{10}$ & -0.0065 \\
$b_{11}$ & 0.0023 \\
$b_{12}$ & 0.0034 \\
$b_{13}$ & 0.0020 \\
$b_{14}$ & 0.0010 \\
$b_{15}$ & -0.0004 \\
$b_{16}$ & -0.0028 \\
$b_{17}$ & -0.0009 \\
$b_{18}$ & 0.0064 \\
\hline &
\end{tabular}

where $\eta$ is the theoretical response, $\beta_{i}(i=1$ to 18$)$ represent theoretical coefficients and $X_{i}(i=1$ to 18$)$ coded variables with two values: -1 and +1 . The model is valid only for these two levels for each factor.

Table 6 shows the values of coefficient estimations $b_{1}, b_{2}, \ldots$.

Active factors can be identified with classical methods used in screening study, such as Lenth approach [32], "normal plot"... Fig. 1 shows the "half normal plot" graph: the eighteen effects are sorted in increasing absolute magnitude; the absolute values of the coefficients are then plotted on a linear scale and the cumulative probabilities on a "probability scale". If none of the effects was active, it would be expected that they would be all normally distributed about zero and the cumulative plot of the effects drawn on "probability paper" would give an approximately straight line.

Most of the points appear to lie on a straight line but the two last points deviate from it as pointed out by the values obtained for coefficient estimates (Table 6). Sixteen factors $\left(U_{1}\right.$, from $U_{3}$ to $U_{6}$ and from $U_{8}$ to $U_{18}$ ) do not significantly influence the

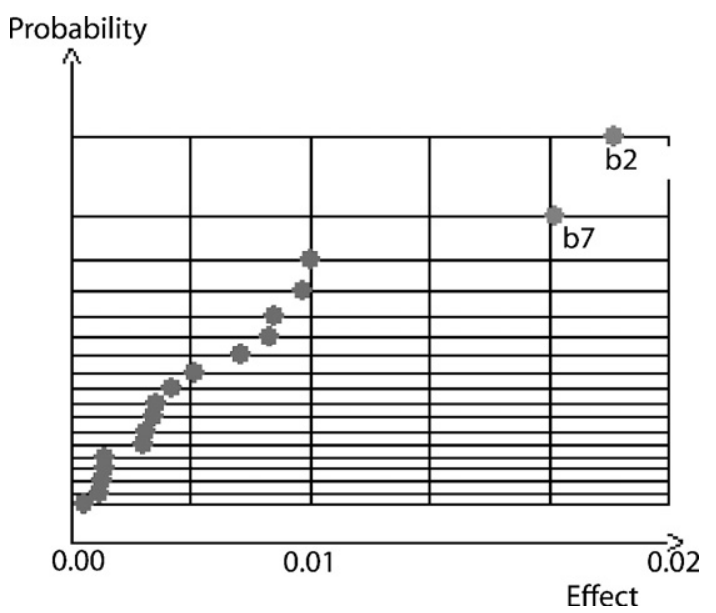

Fig. 1. Half normal plot.
Table 7

Experimental design and results

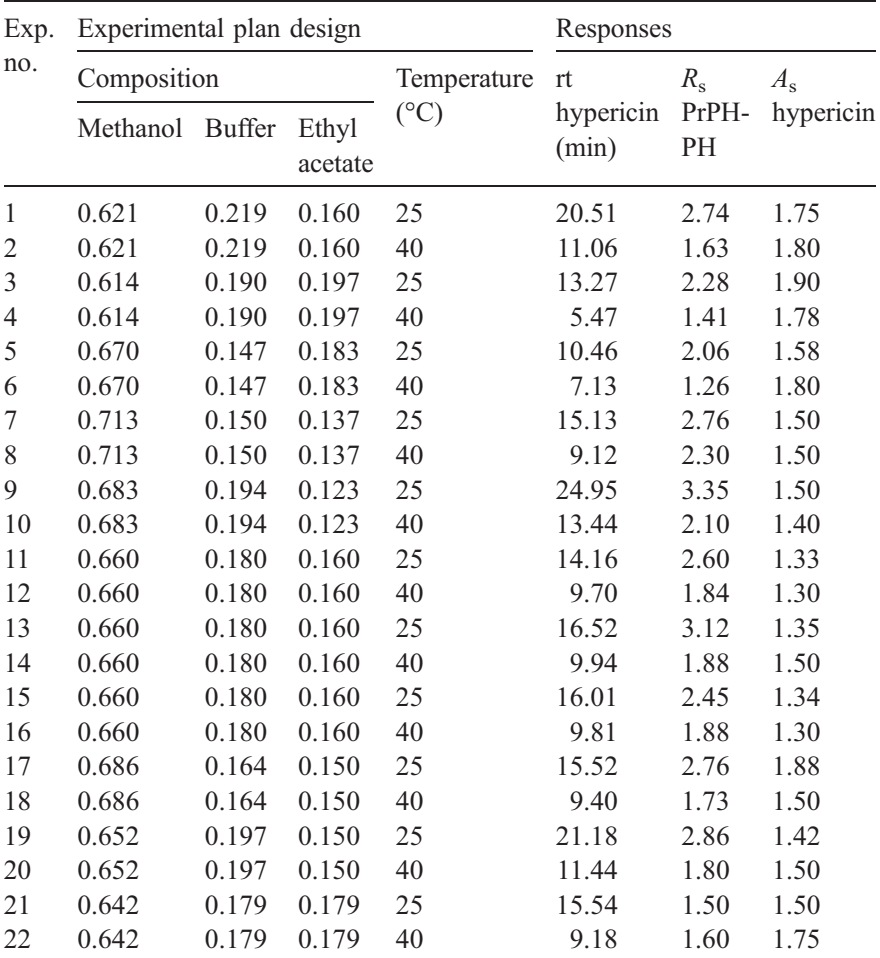

$\mathrm{rt}$ is for retention time.

response: the two tested levels behave in the same way-we can note particularly the case of the two chosen sonication durations $\left(U_{6}\right)$-only the effects of stationary phase $\left(U_{2}\right)$ and type of light $\left(U_{7}\right)$ are active. Analytical steps do not stand all the classical supports used under reversed phase conditions, same results were obtained only with the same type of material like in the previous study when chromatographic phases differ only by their hydrophobicity. However, in the case of light exposure, the use of neon light decreases the response compared with that of the light bulb. The irradiation step-a "daylight exposure" as described in the monograph-lacks experimental details and a result of reproducibility. To overcome this problem it appears necessary to proceed with artificial light with an exact

Table 8

Coefficients of the model represented by Eq. (7) for the three measured responses

\begin{tabular}{lrrr}
\hline Coefficient & \multicolumn{2}{l}{ Response } & \multicolumn{1}{c}{$\mathrm{rt}$} \\
\cline { 2 - 4 } & \multicolumn{1}{c}{$R_{\mathrm{s}}$} & \multicolumn{1}{c}{$A_{\mathrm{s}}$} & 11.842 \\
\hline$b_{1}$ & 2.769 & 1.882 & 35.395 \\
$b_{2}$ & -0.615 & 8.041 & 31.111 \\
$b_{3}$ & 1.261 & 6.673 & 14.626 \\
$b_{12}$ & 4.494 & -10.443 & -44.752 \\
$b_{13}$ & -3.871 & -7.057 & -95.562 \\
$b_{23}$ & 7.357 & -12.748 & -3.086 \\
$b_{14}$ & -0.174 & -0.229 & -21.382 \\
$b_{24}$ & -0.978 & 0.792 & 6.869 \\
$b_{34}$ & -1.667 & -0.687 & 19.107 \\
$b_{124}$ & -1.492 & -0.475 & 51.644 \\
$b_{134}$ & 0.857 & 2.433 & \\
$b_{234}$ & 5.881 & -2.304 &
\end{tabular}



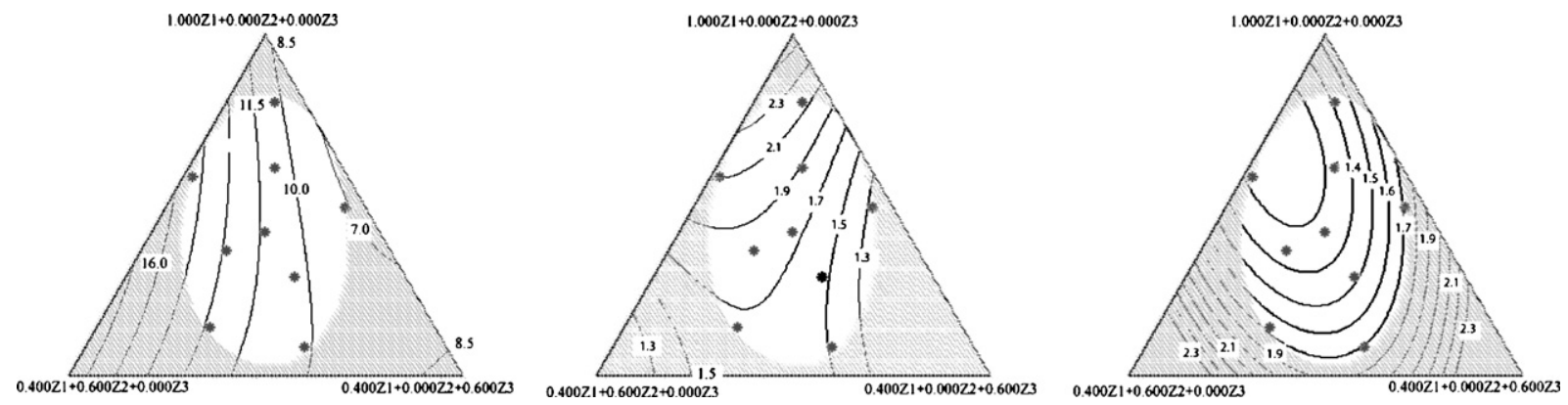

Fig. 2. Isoresponse curves at $40^{\circ} \mathrm{C}$. On the left, for the analysis time, on the middle for the resolution and on the right concerning the asymmetry response.

declaration of wavelength and intensity as described in the literature $[15,33]$ or to either remove this irradiation step. The inconvenience of the first option lies in the availability of this specialized material in a laboratory devoted to routine analysis. Then for the sake of simplicity, we opted for the second alternative.

We used a sequential bifurcation [34] to estimate the method robustness with a minimum number of runs to perform. This chemometric approach deals with non-active factors of the preceding design; all the factors related to the light exposure $\left(U_{3}, U_{4}, U_{7}\right.$ and $\left.U_{12}\right)$ and the type of column $\left(U_{2}\right)$ were excluded. All the experiments were carried out on the endcapped ODS stationary phase to comply with the suitability criterion in terms of peak symmetry. We maintained a change of $30 \%$ between the two levels attributed to the flow rate. Actually, a working value of $1.0 \mathrm{~mL} / \mathrm{min}$ is quite usual in HPLC, but performing the separation at the flow rate inducing the highest number of plate is more appropriate. The sequential bifurcation approach consists in setting on each factor two extreme levels capable to induce the highest response at level $(+)$ and the lowest at level (-). The first step of this chemometric process implies to perform one run with all factors fixed at level $(-)$ and one run with all factors fixed at level (+). If the same response is obtained for both runs, the robustness of the method is claimed. As we removed the irradiation step, the four naphthodianthrones present in SJW need to be expressed as hypericin in order to avoid bias in the results. We obtained average values of hypericins content of $0.186 \pm 0.0055 \%$ from five replicates at levels (-) and $0.190 \pm 0.0071 \%$ from five replicates at levels $(+)$.
The difference between both experiments is non-significant. Then the method is considered as robust for each factor within its variation domain. This robustness study ended the first part of our work devoted to the investigation of the slight modifications we could make to the proposal of the official monograph.

The second part deals with the development of a chemometric methodology for substituting a type of buffer by another one. In order to avoid drastic conditions due to the phosphate buffer in the mobile phase, we substituted it by an acetate buffer at the same $\mathrm{pH}$. The optimum eluent composition was determined with a combined design associating mixture variables and an independent one. The originality of this design lies in the construction around a reference mixture: 66/18/16, methanol/acetate buffer/ethyl acetate, v/v/v. $Z_{1}, Z_{2}$ and $Z_{3}$ notation are attributed to the content of respectively methanol, acetate buffer and ethyl acetate. To avoid increasing the inlet pressure, the maximum variation of the eluent was fixed at $\pm 5 \%$ for $Z_{1}$ and $\pm 4 \%$ for $Z_{2}$ and $Z_{3}$. The temperature $\left(25\right.$ or $\left.40^{\circ} \mathrm{C}\right)$ was added as an independent process variable.

The model based on four predictor variables was built as follows: (i) the three mixture variables are described with a second degree model in the component fraction $Z_{i}$, for the defined domain, a common model in design of experiments for mixture.

$$
\begin{aligned}
\eta_{\text {mix }}= & \beta_{1}^{\prime} Z_{1}+\beta_{2}^{\prime} Z_{2}+\beta_{3}^{\prime} Z_{3}+\beta_{12}^{\prime} Z_{1} Z_{2}+\beta_{13}^{\prime} Z_{1} Z_{3} \\
& +\beta_{23}^{\prime} Z_{2} Z_{3}
\end{aligned}
$$
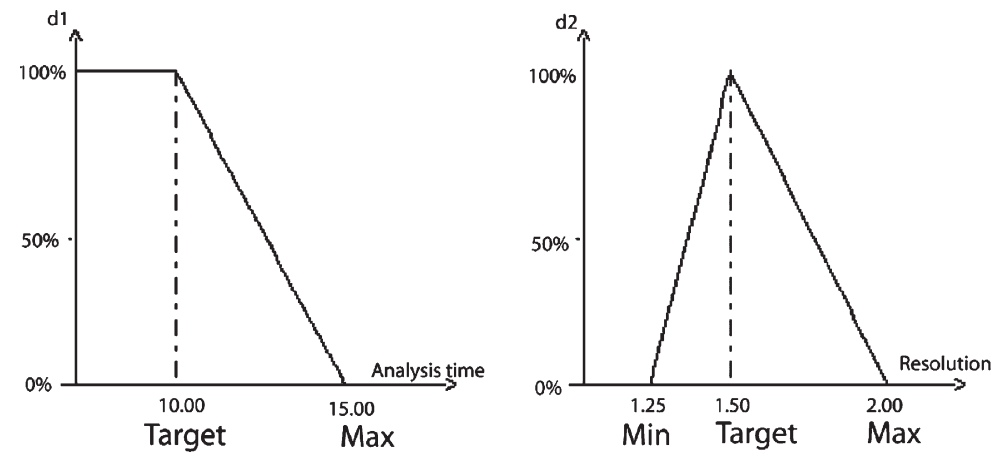

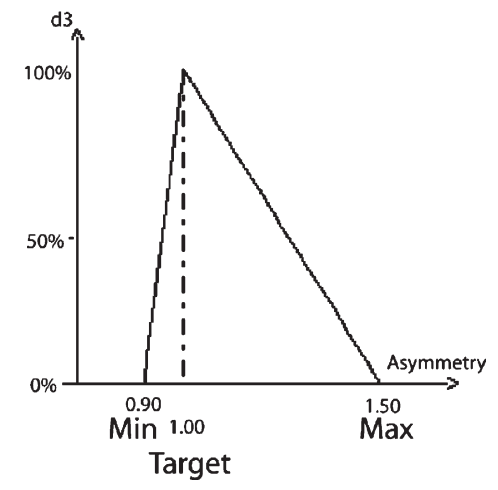

Fig. 3. Desirability functions used to find the optimum mixture. On the left analysis time, on the middle resolution and on the right the hypericin peak asymmetry. 
(ii) The quantitative variable is described with a first degree model using $X_{4}$ to represent the nondimensional coded variables:

$\eta_{\text {ind }}=\beta_{0}+\beta_{4} X_{4}$

Finally, the complete equation model describing the response variation is a multiplicative model, considering that the temperature influence could be different relative to the mixture composition.

$$
\begin{aligned}
\eta= & \eta_{\text {mix }} \times \eta_{\text {ind }} \\
\eta= & \beta_{1} Z_{1}+\beta_{2} Z_{2}+\beta_{3} Z_{3}+\beta_{12} Z_{1} Z_{2}+\beta_{13} Z_{1} Z_{3} \\
& +\beta_{23} Z_{2} Z_{3}+\beta_{14} Z_{1} X_{4}+\beta_{24} Z_{2} X_{4}+\beta_{34} Z_{3} X_{4} \\
& +\beta_{124} Z_{1} Z_{2} X_{4}+\beta_{134} Z_{1} Z_{3} X_{4}+\beta_{234} Z_{2} Z_{3} X_{4}
\end{aligned}
$$

The experimental plan design is presented in Table 7. The variance of experimental error was estimated from six replicates (run nos. 11 to 16) and six test points (runs nos. 17 to 22) were included to check out the accordance of the calculated model with the experiment. The model was built from Eq. (7) and the coefficient estimates using multilinear regression are presented in Table 8.

Three responses have been investigated in our study: (i) the analysis time in terms of retention time of the last compound eluted (hypericin), (ii) the resolution between pseudohypericin and protopseudohypericin and (iii) the asymmetry factor required to check the system suitability. Within the experimental domain of interest, isoresponse curves were drawn from the calculated models-validated with test points-for each requirement at each temperature. We selected the most representative isoresponse curves (Fig. 2). Considering the analysis time, the verticality of isoresponse curves predicts that at both temperatures, the analysis time does not vary when the buffer/ethyl acetate relative proportion ratio is constant.

The compromise between all the responses have been determined using an approach based on the desirability functions [35]: in any point of the domain, predicted response

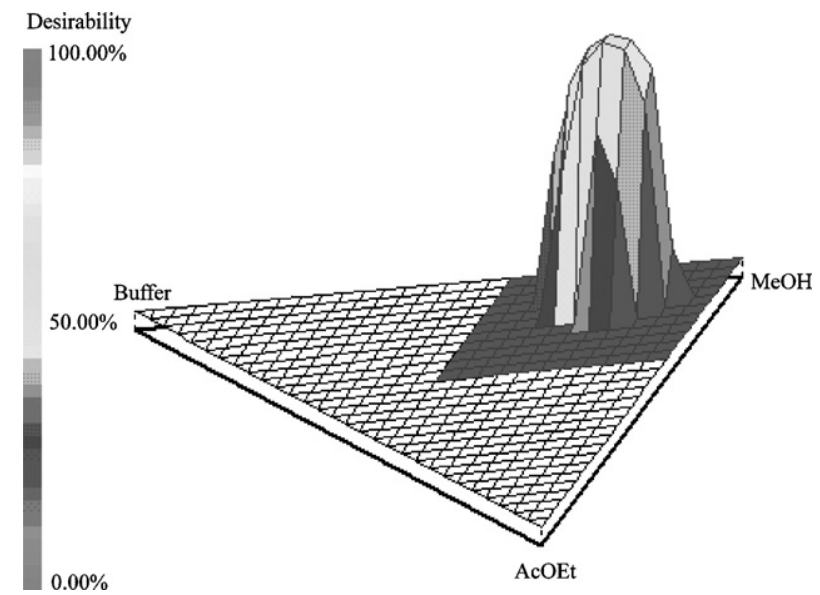

Fig. 4. Response surface of the desirability function and therefore the best compromise and therefore the best composition is obtained at the top of the graph.
Table 9

Predicted and experimental values

\begin{tabular}{lll}
\hline & Predicted responses & Measured responses \\
\hline $\mathrm{rt}(\min )$ & $9.86 \pm 0.74$ & 8.63 \\
$R_{\mathrm{s}}$ & $1.79 \pm 0.17$ & 1.63 \\
$A_{\mathrm{s}}$ & $1.41 \pm 0.12$ & 1.40 \\
\hline
\end{tabular}

values can be transformed into an appropriate desirability function representing the satisfactory versus the response. Partial desirability functions $d_{i}$ are represented in Fig. 3. To minimize the retention time, the desirability function has been set at $100 \%$ from 0 to $10 \mathrm{~min}$ and decreased linearly from 10 to $15 \mathrm{~min}$. Concerning the resolution, the function increases from 1.25 to 1.50 and decreases from 1.50 to 2.00 . The optimum of asymmetry has been fixed at 1.0 and decreased down to 1.5 .

The overall desirability is calculated within the experimental domain, by:

$D=\left(d_{1} \times d_{2} \times \ldots \times d_{n}\right)^{1 / n}$

with $d_{i}=0 \%, d_{i}=100 \%, 0 \%<d_{i}<100 \%$ for respectively undesirable, desirable and acceptable values of the response $i$. When an undesirable value is obtained for one response, the overall desirable value is $0 \%$ and no compromise has been found. On the contrary, when each requirement gets completely satisfied, the overall desirability value is $100 \%$. Finally, when $0 \%<D<100 \%$, an acceptable compromise between the different responses has been found.

The response surface corresponding to desirability function are presented in Fig. 4. The desirability function is maximized around a mixture of 68/16/16, methanol/buffer/ethyl acetate, $\mathrm{v} /$ $\mathrm{v} / \mathrm{v}$, at $40^{\circ} \mathrm{C}$ regardless of an overall desirability of about $42 \%$.

The predicted responses have been tested experimentally (Table 9) and a typical chromatogram is reproduced in Fig. 5.

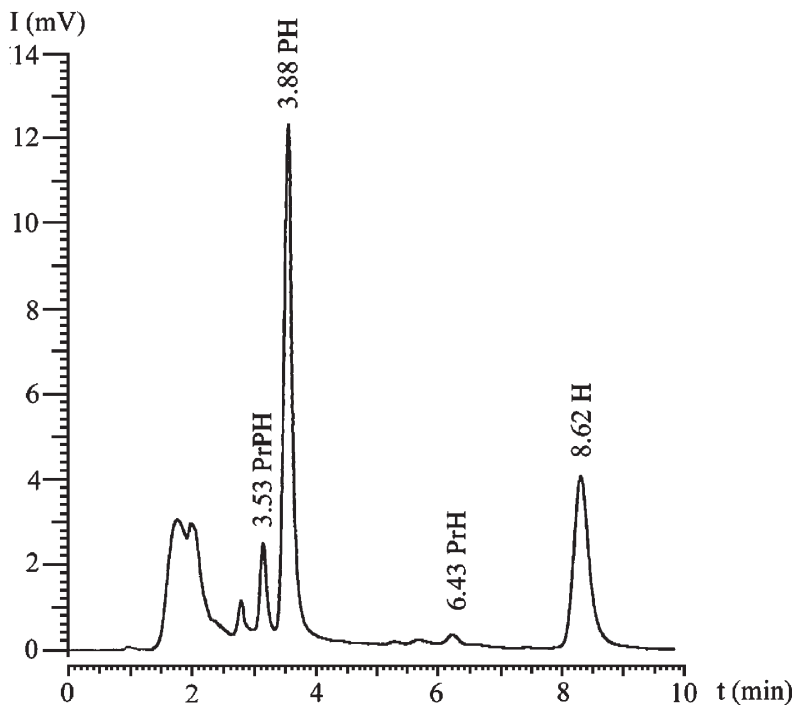

Fig. 5. Chromatogram of a St. John's Wort dry extract. ODS endcapped column, $68 / 16 / 16$, methanol/acetate buffer/ethyl acetate, $\mathrm{v} / \mathrm{v} / \mathrm{v}$, temperature $40^{\circ} \mathrm{C}$, flow rate $0.7 \mathrm{~mL} / \mathrm{min}$, wavelength detection at $590 \mathrm{~nm}$. PrPH=protopseudohypericin, $\mathrm{PH}=$ pseudohypericin, $\mathrm{PrH}=$ protohypericin, $\mathrm{H}=$ hypericin . 


\section{Conclusion}

The chromatographic method offered by the Pharmeuropa to determine hypericins in SJW was original in regard of the light exposure to convert protopseudohypericin and protohypericin respectively to pseudohypericin and hypericin. The first part of our work deals with the investigation of the modifications we could make without introducing major modifications to the proposal of the official monograph. Both asymmetric and screening designs pointed out that a natural or artificial light exposition does not permit to comply with intra-assay precision. Then, we checked out the robustness of the method, free of a random light irradiation, by a sequential bifurcation approach. This modification implies to quantify all protoderivatives expressed as hypericin. The optimized method is easy to implement in a pharmaceutical laboratory for routine analysis and answers to the requirement of the European Pharmacopoeia.

In the second part, we used the example of the naphthodianthron separation to develop a chemometric methodology for substituting a type of buffer by another one. Already phosphate buffer has been widely employed as a usual buffer in HPLC under reversed phase conditions, but its main disadvantage lies in its incompatibility with Mass Spectrometry. Then we proposed a simple process to substitute the phosphate buffer by an acetate one. Analysis time, resolution and asymmetry were predicted from an original combined design built around a reference mixture. The postulated model was validated with test points provided during the design construction. The best compromise was obtained by the way of desirability functions defined on each studied response.

All the chemometric methodologies described here may be applied to resolve the analytical problem of minimizing the number of experiments to perform.

\section{Acknowledgements}

This work was supported by the French Conseil Régional Provence-Alpes-Côte-d'Azur. The authors are also grateful for the financial support received from the Pharmaceutical Laboratory DISTRI B3 (Marseille, France).

\section{References}

[1] J. van Hellemont, In: APB Service Scientifique (Eds.), Compendium de phytothérapie, Masson, Issy les Moulineaux, 1986.

[2] W.E. Muller, Current St. John's Wort research from mode of action to clinical efficacy, Pharmacol. Res. 47 (2003) 101-109.

[3] J.-H. Keller, M. Karas, W.E. Mueller, D.A. Volmer, G.P. Eckert, M.A. Tawab, H.H. Blume, T. Dingermann, M. Schubert-Zsilavecz, Determination of hyperforin in mouse brain by high-performance liquid chromatography/tandem mass spectrometry, Anal. Chem. 75 (2003) 6084-6088.

[4] A. Singer, M. Wonnemann, W.E. Muller, Hyperforin, a major antidepressant constituent of St. John's Wort, inhibits serotonin uptake by elevating free intracellular $\mathrm{Na}^{+}$, J. Pharmacol. Exp. Ther. 290 (1999) $1363-1368$

[5] M. Wonnemann, A. Singer, W.E. Muller, Inhibition of synaptosomal uptake of 3H-L-glutamate and 3H-GABA by hyperforin, a major constituent of St. John's Wort. The role of amiloride sensitive sodium conductive pathways, Neuropsychopharmacology 23 (2000) 188-197.
[6] C. Seger, H. Römpp, S. Sturm, E. Haslinger, P.C. Schmidt, F. Hadacek, Characterization of supercritical fluid extracts of St. John's Wort (Hypericum perforatum L.) by HPLC-MS and GC-MS, Eur. J. Pharm. Sci. 21 (2004) 453-463.

[7] W. Li, J.F. Fitzloff, High performance liquid chromatographic analysis of St. John's Wort with photodiode array detection, J. Chromatogr., B, Biomed. Sci. Appl. 765 (2001) 99-105.

[8] S. Bauer, E. Störmer, H.J. Graubaum, I. Roots, Determination of hyperforin, hypericin and pseudohypericin in human plasma using HPLC analysis with fluorescence and ultraviolet detection, J. Chromatogr., B, Biomed. Sci. Appl. 765 (2001) 29-35.

[9] P. Pietta, C. Gardana, A. Pietta, Comparative evaluation of St. John's Wort from different Italian regions, Il Farmaco 56 (2001) 491-496.

[10] S. Schulte-Löbbert, K. Westerhoff, A. Wilke, M. Schubert-Zsilavecz, M. Wurglics, Development of a HPLC method for the determination of biapigenin in biorelevant media, J. Pharm. Biomed. Anal. 33 (2003) $53-60$.

[11] M. Brolis, B. Gabetta, N. Fuzzati, R. Pace, F. Panzeri, F. Peterlongo, Identification by HPLC-DAD-MS and quantification by HPLC-UV absorbance detection of active constituents of Hypericum perforatum, J. Chromatogr., A 825 (1998) 9-16.

[12] C. Brenier-Maurel, C. Delaurent, G. Pages, M.C. Guilhem, A.M. Siouffi, Optimization of St. John's Wort flavonoid separation by reversed phase liquid chromatography on a silica-based monolithic column, Chromatographia 56 (2002) 277-282.

[13] A.H. Draves, S.E. Walker, Determination of hypericin and pseudohypericin in pharmaceutical preparations by liquid chromatography with fluorescence detection, J. Chromatogr., B, Biomed. Sci. Appl. 749 (2000) 57-66.

[14] F.F. Liu, C. Ang, T. Heinze, J. Rankin, R. Beger, J.P. Freeman, J. Lay Jr., Evaluation of major active components in St. John's Wort dietary supplements by HPLC with photodiode array detection and electrospray MS confirmation, J. Chromatogr., A 888 (2000) 85-92.

[15] T. Sirvent, D.M. Gibson, Rapid isocratic HPLC analysis of hypericins, J. Liq. Chromatogr. Relat. Technol. 23 (2000) 251-259.

[16] Herbal Gram (Ed.), Special Supplement in HerbalGram, American Herbal Pharmacopoeia, Scotts Valley, 1997.

[17] S.H. Hansen, A.G. Jensen, C. Cornett, I. Bjornsdottir, S. Taylor, B. Wright, I. Wilson, HPLC on-line coupled to High-Field NMR and MS for structure elucidation of constituents of Hypericum perforatum L. Anal. Chem. 71 (1999) 5235-5241.

[18] A. Tolonen, J. Uusitalo, A. Hohtola, J. Jalonen, Determination of naphthodianthrones and phloroglucinols from Hypericum perforatum extracts by liquid chromatography/tandem mass spectrometry, Rapid Commun. Mass Spectrom. 16 (2002) 396-402.

[19] P. Avato, G. Guglielmi, Determination of major constituents in St. John's Wort under different extraction conditions, Pharm. Biol. 42 (2004) 83-89.

[20] J. Bruneton, in: Lavoisier (Ed.), Pharmacognosie, Phytochimie, Plantes médicinales, Tec and Doc, Paris, 1999.

[21] In: Council of Europe (Eds.), European Pharmacopeia, Council of Europe, Strasbourg, 2002.

[22] In: Deutscher Arzneimittel-Codex, Deutscher Apotheker Verlag, Stuttgart, 1991.

[23] In: Council of Europe (Eds.), Millepertuis (Extrait sec quantifié de), Council of Europe, Strasbourg, 2004, pp. 112-113.

[24] R.B. Waters, A. Dovletoglou, Evaluating HPLC assay robustness with experimental design, J. Liq. Chromatogr. Relat. Technol. 26 (2003) 2975-2985.

[25] E. Hund, Y. Vander Heyden, M. Haustein, D.L. Massart, J. SmeyersVerbeke, Robustness testing of a reversed-phase high-performance liquid chromatographic assay: comparison of fractional and asymmetrical factorial designs, J. Chromatogr., A 874 (2000) 167-185.

[26] J. Vial, A. Jardy, Use of experimental designs to evaluate the robustness of a quantitative HPLC method, Analusis 26 (1998) 15-24.

[27] M. Feinberg, in: Dunod (Ed.), La validation des méthodes d'analyse: une approche chimiomètrique de l'assurance qualité au laboratoire, Dunod, Paris, 1996, p. 416. 
[28] D. Mathieu, J. Nony, R. Phan-Tan-Luu, Nemrodw, LPRAI, Marseille, 1998.

[29] S. Addelman, Orthogonal main-effect plans for asymmetrical factorial experiments, Technometrics 4 (1962) 21-46.

[30] C. Cativiela, J. Elguero, D. Mathieu, E. Melendez, R. Phan-Tan-Luu, Application de méthodes modernes de construction de matrices d'expériences aux modèles de Free-Wilson, Eur. J. Med. Chem. 4 (1983) 359-363.

[31] R.-L. Plackett, J.-P. Burman, Design of optimum multifactorial experiments, Biometrika 33 (1943) 305-325.

[32] R.V. Lenth, Quick and easy analysis of unreplicated factorials, Technometrics 31 (1989) 469-473.
[33] A. Michelitsch, B. Biza, M. Wurglics, M. Schubert-Zsilavecz, A. Baumeister, W. Likussar, Determination of hypericin in herbal medicine products by differential pulse polarography, Phytochem. Anal. 11 (2000) $41-44$.

[34] B. Bettonvil, J.P.C. Kleijnen, Searching for important factors in simulation models with many factors: sequential bifurcation, Eur. J. Oper. Res. 96 (1997) $180-194$.

[35] G. Derringer, R. Suich, Simultaneous optimization of several response variables, J. Qual. Technol. 12 (1980) 214-219. 